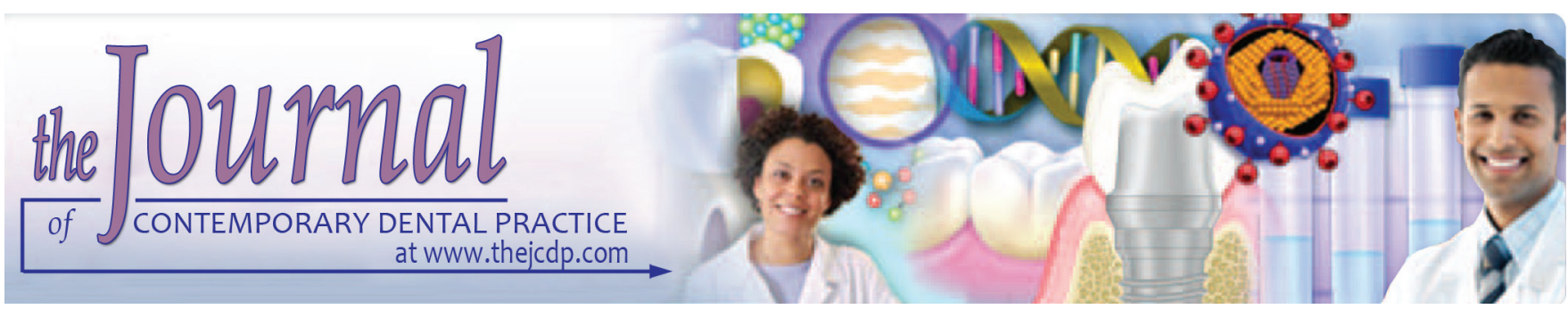

\title{
Effect of At-home and In-office Bleaching on Marginal Microleakage in Composite Resin Restorations using Two Adhesive Systems
}

${ }^{1}$ Celso A Klein Jr, ${ }^{2}$ Douglas da Silva, ${ }^{3}$ Eduardo G Reston, ${ }^{4}$ Diana LB Borghetti, ${ }^{5}$ Roberto Zimmer

\begin{abstract}
Aim: The aim of this study is to assess marginal microleakage of cervical cavities restored with composite resins and two different adhesive techniques subjected to at-home and in-office bleaching.
\end{abstract}

Materials and methods: In this randomized, blind laboratory experiment, 60 bovine teeth recently extracted were collected and divided into six groups ( $n=10$ each group). The teeth received cervical cavity preparations $(2 \mathrm{~mm} \times 3 \mathrm{~mm} \times 1 \mathrm{~mm})$ with enamel margins. Two different adhesive systems were used (Single Bond 2 and Clearfil SE Bond), in addition to composite resin (Z250). Restored teeth received two different bleaching gels (Opalescence PF and Opalescence Boost). Teeth were thermocycled and analyzed under confocal laser scanning microscopy.

Results: No significant differences were observed $(p>0.05)$ in microleakage scores between the two groups not subjected to bleaching nor between the four groups that received bleaching treatment $(p>0.05)$, regardless of the gel and adhesive system employed. However, when comparing nonbleached with bleached teeth, those not subjected to bleaching showed statistically lower marginal microleakage scores $(p<0.05)$. Data were statistically analyzed using the Kruskal-Wallis test followed by Student-Newman-Keuls post hoc test, with significance set at $5 \%$.

Conclusion: Marginal microleakage in composite resin restorations is influenced by the action of bleaching agents used both at-home and in-office, regardless of the adhesive system employed (total-etch or self-etch).

Clinical significance: Both at-home and in-office bleaching agents have an influence on the adhesive interface of resin restorations, producing changes and inducing marginal leakage.

\footnotetext{
${ }^{1-5}$ Department of Operative Dentistry, Universidade Luterana do Brasil, Canoas, Rio Grande do Sul, Brazil

Corresponding Author: Celso A Klein Jr, Department of Operative Dentistry, Universidade Luterana do Brasil, Canoas Rio Grande do Sul, Brazil, Phone: +5551999687105, e-mail: profcelsoklein@gmail.com
}

Keywords: Adhesive systems, Class $\mathrm{V}$ cavities, Laboratory research, Microleakage, Tooth bleaching.

How to cite this article: Klein Jr CA, da Silva D, Reston EG, Borghetti DLB, Zimmer R. Effect of At-home and In-office Bleaching on Marginal Microleakage in Composite Resin Restorations using Two Adhesive Systems. J Contemp Dent Pract 2018;19(3):248-252.

Source of support: This study received financial support from Universidade Luterana do Brasil (ULBRA).

Conflict of interest: None

\section{INTRODUCTION}

Tooth bleaching has become very popular over the past few decades, and it is currently one of the esthetic dental treatments most commonly delivered. As it is a simple, conservative, effective procedure for the removal of intrinsic stains present on teeth, bleaching is widely performed by both general and specialist dental practitioners. ${ }^{1,2}$ At present, tooth bleaching techniques are basically limited to the application of two types of bleaching gels: Carbamide peroxide and hydrogen peroxide. In vital teeth, both peroxides may be used either in the office, applied by the dentist (in-office bleaching), or at the patient's home (at-home bleaching) the latter also requires supervision by a dentist. ${ }^{3}$

When the bleaching agent is applied on the tooth surface, it penetrates the enamel layer, through interprismatic spaces, and also the dentin, through dentinal tubules. ${ }^{4-6}$ Carbamide or hydrogen peroxide act through a complex oxidation reaction, according to Fick's second diffusion law, ${ }^{7}$ releasing oxygen with extremely low molecular weight. This oxygen reacts and chemically degrades chromogens, making them soluble and expelling them by diffusion. ${ }^{2,8}$ As a result, the tooth becomes free from pigments and consequently lighter in color. ${ }^{9-11}$

If, on the one hand, bleaching gels are in contact with tooth structures, on the contrary, they also act on restorative 
Table 1: Material, manufacturer, composition, and application

\begin{tabular}{|c|c|c|c|}
\hline Product & Manufacturer & Composition & Application \\
\hline $\begin{array}{l}\text { Adper single bond } 2 \text { total- } \\
\text { Etch-SB }\end{array}$ & 3M ESPE & $\begin{array}{l}\text { 2,2-Bis-[4-(2-hydroxy-3-methacryloxypropoxy)phenyl]- } \\
\text { propane, 2-hydroxyethyl methacrylate (HEMA), } \\
\text { dimethacrylates, ethanol, water, polyacrylic and } \\
\text { polyalcenoic acid methacrylate }\end{array}$ & $\begin{array}{l}\text { Phosphoric acid (15s), rinsing } \\
\text { (10s), air drying, adhesive } \\
\text { application (15s), air jet (5s), } \\
\text { and light-curing (10s) }\end{array}$ \\
\hline Clearfil SE bond & Kuraray & $\begin{array}{l}\text { Primer: HEMA, hydrophilic dimethacrylate, 10-MDP, N, } \\
\text { N-diethyl-p-toluidine, camphorquinone, water. } \\
\text { Adhesive: Silane silica, Bis-GMA, 10-MDP, HEMA, } \\
\text { hydrophilic dimethacrylate, toluidine, camphorquinone }\end{array}$ & $\begin{array}{l}\text { Primer application (20s), air } \\
\text { drying, adhesive application } \\
\text { and light-curing (10s) }\end{array}$ \\
\hline Opalescence PF & Ultradent & Carbamide peroxide $20 \%$ & $3 \mathrm{hr} /$ day for 15 days \\
\hline Opalescence boost & Ultradent & Hydrogen peroxide $40 \%$ & $\begin{array}{l}2 \text { applications } / 15 \text { min each } \\
\text { for } 2 \text { days }\end{array}$ \\
\hline
\end{tabular}

materials and their adhesive interface. Several studies have been performed to investigate the possible deleterious effects of peroxides on restorative materials, ${ }^{12-14}$ especially on the bonding of the composite resin to the tooth structure, which could affect marginal sealing. ${ }^{15-22}$ Some of those studies have demonstrated that bleaching gels negatively affect bond strength in restored teeth. ${ }^{23,24}$ Poor sealing and decreased bond strength lead to marginal microleakage, causing the penetration of bacteria, liquids, molecules, and ions into the tooth/restoration interface. ${ }^{25}$ Therefore, some authors advocate the use of total-etch adhesive systems in teeth that will be restored and later subjected to bleaching. ${ }^{17,20,21}$

The aim of this study was to assess, using confocal laser scanning microscopy, marginal microleakage in bovine teeth with cervical cavities restored with composite resins, and two different adhesive techniques and subjected to at-home and in-office bleaching.

\section{MATERIALS AND METHODS}

This was a randomized, blind laboratory experiment. Sixty bovine anterior teeth with no carious lesions were selected, cleaned, and stored in thymol solution $0.2 \%$ for 30 days. Cervical cavity preparations $(2 \mathrm{~mm} \times 3 \mathrm{~mm} \times$ $1 \mathrm{~mm}$ ) were performed using a ${ }^{\#} 3131$ bur (KG Sorensen, Cotia, São Paulo, Brazil), with air coolant, on the buccal surface, short of the cementoenamel junction, with enamel margins on all four sides. The adhesive systems and bleaching gels used are described in Table 1. Single Bond 2 (3M ESPE, Saint Paul, Minnesota, USA) or Clearfil SE Bond (Kuraray, New York, USA) was used according to the manufacturers' instructions. In the Clearfil SE Bond group, enamel acid etching was not performed.

Cavities were restored using the incremental technique with Filtek Z250 shade A2 (3M ESPE, Saint Paul, Minnesota, USA), at a total of 3 equal increments, each one light-cured for 20 seconds (Coltolux II, Coltene, St. Gallen, Switzerland). All restorations were finished and polished using polishing disks (Soflex; 3M ESPE). Then, all restored teeth were subjected to thermocycling
Table 2: Group description: bleaching agents and adhesive systems employed

\begin{tabular}{lll}
\hline Group & Bleaching agent & Adhesive system \\
\hline I & Control (no bleaching) & Single bond 2 \\
II & Control (no bleaching) & Clearfil SE bond \\
III & Opalescence PF & Single bond 2 \\
IV & Opalescence PF & Clearfil SE bond \\
V & Opalescence boost & Single bond 2 \\
VI & Opalescence boost & Clearfil SE bond \\
\hline
\end{tabular}

(MpBased, KARA 1000, Tehran, Iran) for 500 cycles between $5 \pm 2$ and $55 \pm 2{ }^{\circ} \mathrm{C}$, with hold times of 30 seconds at each temperature and 10 seconds at each temperature change. Six groups with 10 teeth each were formed, as shown in Table 2.

Restored teeth received the bleaching gels Opalescence PF and Opalescence Boost (Ultradent, South Jordan, Utah, USA) according to the manufacturer's instructions, also described in Table 1. Briefly, the at-home bleaching gel was applied and maintained in contact with the teeth 3 hours / day, for 15 days. After the 3-hour application, the gel was removed using water/air spray. The teeth were maintained in an environment with $50 \%$ relative humidity throughout the 15 days. The in-office gel was applied and maintained in contact with the teeth for 15 minutes, then rinsed and applied again for another 15 minutes, at a total of 30 minutes. This procedure was performed on two different days at a 1-week interval.

After this stage, the apical foramina of the teeth were sealed with wax and gutta-percha, and the tooth surfaces, including the foramina, were covered with two layers of nail polish, except for the restoration areas, as of $1 \mathrm{~mm}$ from the margins. Specimens were then immersed in 0.1 M rhodamine B solution (Aldrich Chem. Co., Milwaukee, Wisconsin, USA) for 48 hours, not alternating with water. Then, teeth were stored in water and longitudinally sectioned in buccal-lingual direction using a diamond disk sander (Denta rapid, Krupp Dental 759 DR 2, Hilzingen, Germany), grounded with 500, 1000, 1500, and 2000 grit sandpaper (3M ESPE), and washed in an ultrasonic cleaner (L100, Schuster, Santa Maria, Rio Grande do Sul, Brazil). 
Specimens were analyzed under confocal laser scanning microscopy (Fluoview ${ }^{\mathrm{TM}}$ 1000; OLYMPUS Corporation, Japan), using argon laser at an excitation wavelength of $635 \mathrm{~nm}$. The areas were scanned between 10 and $50 \mu \mathrm{m}$ below the treated surface to reduce the influence of the smear layer created during the sectioning and polishing process. The area of fluorescence was quantified using an image analysis system (Fluoview viewer; University of Minnesota, Minnesota, USA).

The following microleakage scores were used to assess the extent of dye penetration into the cavity walls: ${ }^{26}$ $0=$ no dye penetration; $1=$ dye penetration covering less than half of the distance to the axial wall; $2=$ dye penetration covering more than half of the distance to the axial wall, but not reaching the axial wall; and $3=$ dye penetration into the axial wall.

\section{Statistical Analysis}

Data were analyzed using Kruskal-Wallis test, followed by Student-Newman-Keuls post hoc test, with significance set at $5 \%$.

\section{RESULTS}

All groups presented marginal microleakage. The scores obtained in each group are shown in Table 3 and Graph 1. There were no significant differences in the microleakage scores obtained between the two control groups or between the four groups subjected to bleaching (regardless of the type of bleaching agent or adhesive system employed). Conversely, differences were found when the control groups were compared with the experimental groups, with the former showing lower microleakage scores than the latter.

\section{DISCUSSION}

Marginal microleakage tests are widely used to assess the quality of adhesion in composite resin restorations, ${ }^{27,28}$ and they are extremely important to identify negative

Table 3: Microleakage scores obtained in each group and median score

\begin{tabular}{lllllll}
\hline & & \multicolumn{4}{c}{ Microleakage score } & \\
\cline { 3 - 5 } Group & $n$ & 0 & 1 & 2 & 3 & Median \\
\hline $\mathrm{I}^{\mathrm{A}}$ & 10 & 4 & 5 & 1 & 0 & 1.0 \\
$\mathrm{II}^{\mathrm{A}}$ & 10 & 3 & 6 & 1 & 0 & 1.0 \\
$\mathrm{III}$ & 10 & 0 & 1 & 4 & 5 & 2.5 \\
$\mathrm{IV}^{\mathrm{B}}$ & 10 & 0 & 0 & 4 & 6 & 3.0 \\
$\mathrm{~V}^{\mathrm{B}}$ & 10 & 0 & 2 & 1 & 7 & 3.0 \\
$\mathrm{VI}^{\mathrm{B}}$ & 10 & 0 & 0 & 2 & 8 & 3.0 \\
\hline
\end{tabular}

Kruskal-Wallis followed by Student-Newman-Keuls post hoc test. Letters indicate intergroup comparison through post hoc analysis. Groups followed by the same letter are not significantly different $(p>0.05)$

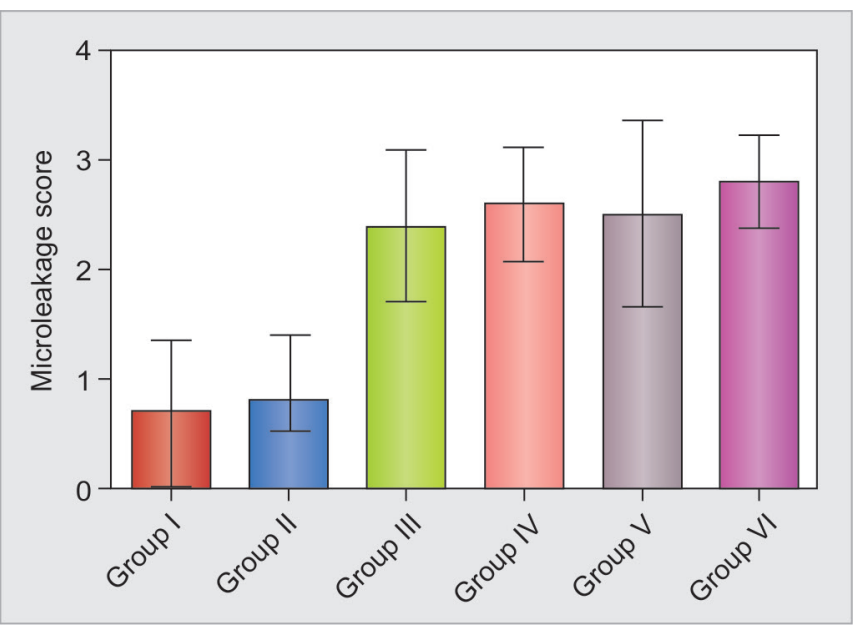

Graph 1: Microleakage scores (median and interquartile range) obtained in each group

consequences of polymerization contraction in composite resins and to evaluate marginal sealing. When aging is present, marginal microleakage tests also allow to evaluate the long-term quality of the bond, provided the applicable cavity standardization and preparation norms are followed. ${ }^{29}$ For the scope of this study, bovine teeth were used because they have an enamel and dentin structure very similar to that of human teeth, in addition to being easily obtainable and handled. ${ }^{27-29}$ In the present study, all experimental stages, from tooth selection, through cavity preparation, restorative technique, and bleaching technique up to specimen preparation, were performed by a single trained, experienced operator. This one-operator approach allowed to eliminate any bias that could influence final results, as the outcomes of restorative techniques are known to be extremely dependent on operator ability and experience.

All groups subjected to bleaching scored 3 for microleakage, meaning that the dye penetrated into the axial wall. One possible explanation for this finding is that, as bleaching products penetrated into the axial wall, they opened a gap for pigments to penetrate as well. Therefore, the oxygen released in the peroxide oxidation reaction may not only chemically degrade the chromogens ${ }^{2}$ but also slightly degrade the dentin/adhesive interface, causing spaces to increase in the interface. We believe that the occurrence of nanoleakage into the adhesive interface causes the released oxygen to penetrate and slowly expand, gradually increasing in size, from a nanofailure to a microfailure, thus resulting in microleakage. In this scenario, a clinical speculation could be that the diffusion of $\mathrm{H}_{2} \mathrm{O}_{2}$ to the axial wall may be one of the factors responsible for postoperative sensitivity or pain caused by the toxic effects of this chemical on pulp cells. ${ }^{14}$ This fact may be correlated with the literature, which shows that $70 \%$ of the patients subjected to bleaching complain of postoperative sensitivity. ${ }^{30}$ 
When the effects of bleaching agents were compared with regard to the adhesive system employed (self-etch vs total-etch), no significant differences were found, i.e., marginal microleakage with penetration into the axial walls was observed in all groups subjected to bleaching. This finding suggests that bleaching agents and their byproducts are able to penetrate and perhaps modify the hybrid layer of the restoration area, affecting the quality of adhesion. The literature on this topic is scarce, and some authors ${ }^{17}$ advocate the use of the traditional adhesive system, i.e., total-etch, due to the increased resin-enamel bond strength of this system, consequently improving marginal sealing against bleaching agents. For instance, Mortazavi et $\mathrm{al}^{31}$ concluded that bleaching agents affected marginal sealing in composite resin restorations made with self-etch adhesive systems. Those authors emphasized on the importance of using total-etch adhesion in restorations that will later be subjected to bleaching with carbamide peroxide products. However, this was not confirmed in our study: Rather, all groups showed marginal microleakage after exposure to bleaching agents.

Penetration of hydrogen peroxide bleaching gels toward and into the pulp is also dependent on enamel and dentin thickness, ${ }^{6}$ as thin layers (e.g., in mandibular incisors vs premolars) make it easier for bleaching gels to reach the pulp. In the present study, all the teeth subjected to bleaching gels, even those with thick enamel and dentin layers, showed dye penetration into the axial wall, suggesting that bleaching gels are aggressive to the dentin/ adhesive interface. Therefore, it is extremely important to conduct a detailed assessment of the clinical status of previous restorations so as to prevent future sensitivity.

Crim, ${ }^{15}$ in turn, using human teeth with cervical cavities restored with composite resin and total-etch adhesives, found that carbamide peroxide bleaching gels applied 2 hours daily for 9 days negatively affected marginal sealing, inducing microleakage. In the present study, carbamide peroxide gel was applied 3 hours daily. The literature presents conflicting findings about the effects of bleaching agents on the marginal seal of composite resin restorations, regardless of the type of adhesive employed (total-etch vs self-etch) and composite resin composition (silorane based vs methacrylate based). ${ }^{32}$ We believe that application time and bleaching agent concentration are the determinants of marginal microleakage. More studies are warranted to assess different application times.

Finally, when comparing the use of at-home vs inoffice bleaching agents, no differences were found, i.e., marginal sealing was affected regardless of the type of gel employed. Again, we believe that the release of oxygen is the factor responsible for inducing marginal microleakage, regardless of the type of bleaching system employed.
Therefore, microleakage seems more likely related with application time and product concentration.

In sum, the present findings underscore the important role of dental practitioners in warning patients with restored teeth about the possible sensitivity issues that may result from the use of bleaching agents, regardless of the technique used during restoration. In this sense, tooth bleaching seems to be dependent on several important factors, related to both the patient and the dental practitioner, rather than exclusively dependent on the type of adhesive system employed in the restoration, or the type of bleaching gel used previously.

\section{CONCLUSION}

Marginal microleakage in composite resin restorations is influenced by the action of bleaching gels applied both at home and in the office, regardless of the adhesive system employed (total-etch or self-etch).

\section{CLINICAL SIGNIFICANCE}

Both at-home and in-office bleaching agents have an influence on the adhesive interface of resin restorations, producing changes and inducing marginal leakage.

\section{REFERENCES}

1. Haywood VB, Heymann HO. Nightguard vital bleaching. Quintessence Int 1989 Mar;20(3):173-176.

2. Haywood VB. History, safety, and effectiveness of current bleaching techniques and applications of the nightguard vital bleaching technique. Quintessence Int 1992 Jul;23(7):471-488.

3. Amato M, Scaravilli MS, Farella M, Riccitiello F. Bleaching teeth treated endodontically: long-term evaluation of a case series. J Endod 2006 Apr;32(4):376-378.

4. Seale NS, Wilson CF. Pulpal response to bleaching of teeth in dogs. Pediatr Dent 1985 Sep;7(3):209-214.

5. Nathanson D. Vital tooth bleaching: sensitivity and pulpal considerations. J Am Dent Assoc 1997 Apr;128 Suppl:41S-44S.

6. Costa CA, Riehl H, Kina JF, Sacono NT, Hebling J. Human pulp responses to in-office tooth bleaching. Oral Surg Oral Med Oral Pathol Oral Radiol Endod 2010 Apr;109(4):e59-e64.

7. Crank, J. The mathematics of diffusion. Oxford: Oxford University Press; 1975.

8. Borges AB, Batista GR, Arantes PT, Wiegand A, Attin T, Torres CR. Influence of simulated pulpal pressure on efficacy of bleaching gels. J Contemp Dent Pract 2014 Jul;15(4):407-412.

9. Türkün M, Kaya AD. Effect of $10 \%$ sodium ascorbate on the shear bond strength of composite resin to bleached bovine enamel. J Oral Rehabil 2004 Dec;31(12):1184-1191.

10. Carey CM. Tooth whitening: what we now know. J Evid Based Dent Pract 2014 Jun;14 Suppl:70-76.

11. Kwon SR, Wertz PW. Review of the mechanism of tooth whitening. J Esthet Restor Dent 2015 Sep-Oct;27(5):240-257.

12. Bueno RP, Viaro PS, Nascimento PC, Pozzobon RT. Ion release from a composite resin after exposure to different $10 \%$ carbamide peroxide bleaching agents. J Appl Oral Sci 2012 May-Jun;20(3):335-339. 
13. Polydorou O, Beiter J, König A, Hellwig E, Kümmerer K. Effect of bleaching on the elution of monomers from modern dental composite materials. Dent Mater 2009 Feb;25(2):254-260.

14. Mourouzis P, Koulaouzidou EA, Helvatjoglu-Antoniades M. Effect of in-office bleaching agents on physical properties of dental composite resins. Quintessence Int 2013 Apr;44(4): 295-302.

15. Crim GA. Post-operative bleaching: Effect on microleakage. Am J Dent 1992 Apr;5(2):109-112.

16. Owens BM, Rowland CC, Brown DM, Covington JS. 3rd. Postoperative dental bleaching: Effect of microleakage on class V tooth colored restorative materials. J Tenn Dent Assoc 1998 Oct;78(4):36-40.

17. Miyazaki M, Sato M, Onose H. Durability of enamel bond strength of simplified bonding systems. Oper Dent 2000 Mar-Apr;25(2):75-80.

18. Miyazaki M, Sato H, Sato T, Moore BK, Platt JA. Effect of a whitening agent application on enamel bond strength of selfetching primer systems. Am J Dent 2004 Jun;17(3):151-155.

19. Breschi L, Cadenaro M, Antoniolli F, Visintini E, Toledano M, Di Lenarda R. Extent of polymerization of dental bonding systems on bleached enamel. Am J Dent 2007 Aug;20(4): 275-280.

20. Gurgan S, Alpaslan T, Kiremitci A, Cakir FY, Yazici E, Gorucu J. Effect of different adhesive systems and laser treatment on the shear bond strength of bleached enamel. J Dent 2009 Jul;37(7):527-534.

21. Kumar AA, Hariharavel VP, Narayanan A, Murali S. Effect of protective coating on marginal integrity of nanohybrid composite during bleaching with carbamide peroxide: A microleakage study. Indian J Dent Res 2015 Mar-Apr;26(2): 167-169.

22. Ulukapi H, Benderli Y, Ulukapi I. Effect of pre-and postoperative bleaching on marginal leakage of amalgam and composite restorations. Quintessence Int 2003 Jul-Aug;34(7):505-508.
23. Cavalli V, de Carvalho RM, Giannini M. Influence of carbamide peroxide-based bleaching agents on the bond strength of resin-enamel/dentin interfaces. Braz Oral Res 2005 Jan-Mar;19(1):23-29.

24. Khoroushi M, Aghelinejad S. Effect of postbleaching application of an antioxidant on enamel bond strength of three different adhesives. Med Oral Patol Oral Cir Bucal 2011 Nov;16(7):e990-e996.

25. Ajami AA, Bahari M, Oskoee SS, Kimyai S, Kahnamoui MA, Rikhtegaran S, Ghaffarian R. Effect of three different mouthrinses on microleakage of composite resin restorations with two adhesive systems after bleaching with 10\% carbamide peroxide. J Contemp Dent Pract 2012 Jan;13(1):16-22.

26. Retief DH. Standardizing laboratory adhesion tests. Am J Dent 1991 Oct;4(5):231-236.

27. Raskin A, D'Hoore W, Gonthier S, Degrange M, Déjou J. Reliability of in vitro microleakage tests: a literature review. J Adhes Dent 2001 Winter;3(4):295-308.

28. Heintze SD. Systematic reviews: I. The correlation between laboratory tests on marginal quality and bond strength. II. The correlation between marginal quality and clinical outcome. J Adhes Dent 2007 Feb;9(Suppl 1):77-106.

29. International Organization for Standardization. Dental materials-testing of adhesion to tooth structure. Geneva: ISO; 2003.

30. Buchalla W, Attin T. External bleaching therapy with activation by heat, light or laser - a systematic review. Dent Mater 2007 May;23(5):586-596.

31. Mortazavi V, Fathi M, Soltani F. Effect of postoperative bleaching on microleakage of etch-and-rinse and self-etch adhesives. Dent Res J (Isfahan) 2011 Winter;8(1):16-21.

32. Hashemikamangar SS, Ghavam M, Mahinfar N, Kharazi Fard MJ. Effect of 30\% hydrogen peroxide on marginal integrity of silorane-based versus methacrylate-based composite restorations. J Dent (Tehran) 2014 Sep;11(5):545-553. 